\title{
Developing Entrepreneurial Thinking in Engineering Students by Utilizing Integrated Online Modules
}

\section{Dr. Ronald S Harichandran P.E., University of New Haven}

Ron Harichandran is Dean of the Tagliatela College of Engineering and is the PI of the grant entitled Developing Entrepreneurial Thinking in Engineering Students by Utilizing Integrated Online Modules and a Leadership Cohort. Through this grant entrepreneurial thinking will be integrated into courses spanning all four years in seven ABET accredited engineering and computer science BS programs.

\section{Dr. Maria-Isabel Carnasciali, University of New Haven}

Maria-Isabel Carnasciali is an Assistant Professor of Mechanical Engineering at the Tagliatela College of Engineering, University of New Haven, CT. She obtained her Ph.D. in Mechanical Engineering from Georgia Tech in 2008. She received her Bachelors of Engineering from MIT in 2000. Her research focuses on the nontraditional engineering student - understanding their motivations, identity development, and impact of prior engineering-related experiences. Her work dwells into learning in informal settings such as summer camps, military experiences, and extra-curricular activities. Other research interests involve validation of CFD models for aerospace applications as well as optimizing efficiency of thermal-fluid systems.

\section{Dr. Nadiye O. Erdil, University of New Haven}

Nadiye O. Erdil is an assistant professor of industrial engineering and engineering and operations management at the University of New Haven. Her research interests include use of statistical methods and lean tools for quality and process improvement, and use of information technology in operations management. Her work is primarily in manufacturing and healthcare delivery operations.

\section{Dr. Cheryl Q Li, University of New Haven \\ Dr. Jean Nocito-Gobel, University of New Haven}

Jean Nocito-Gobel, Professor of Civil \& Environmental Engineering at the University of New Haven, received her Ph.D. from the University of Massachusetts, Amherst. She has been actively involved in a number of educational initiatives in the Tagliatela College of Engineering including KEEN and PITCH, and is the coordinator for the first-year Intro to Engineering course. Her professional interests include modeling the transport and fate of contaminants in groundwater and surface water systems, as well as engineering education reform.

\section{Dr. Samuel D. Daniels P.E., University of New Haven}




\title{
Developing Entrepreneurial Thinking in Engineering Students by Utilizing Integrated Online Modules
}

\begin{abstract}
An approach to develop entrepreneurial thinking skills in engineering students by integrating online modules into existing courses is described. Eighteen online modules covering a variety of topics will be developed. Developers for the modules are selected by reviewing proposals submitted in response to a broadly distributed request for proposals. Developers undergo extensive training before embarking upon module development. Students will complete each standalone module outside of class hours. Instructors who deploy a module in their course will develop contextual course assignments that reinforce concepts covered in the modules. These instructors also undergo training and are assisted by an external consultant. All engineering students will complete at least 13 of the 18 modules; some will complete all 18 modules.
\end{abstract}

\section{Introduction}

Engineering graduates who will be leaders in today's rapidly changing environment must possess an entrepreneurial mindset and a variety of professional skills in addition to technical knowledge and skills. Efforts at developing technical communication, project management, and teamwork skills have been underway at many institutions over the last decade. A newer initiative is the development of entrepreneurial thinking skills. ${ }^{1-3}$ At its core, entrepreneurial thinking requires: (1) insatiable curiosity to investigate a rapidly changing world; (2) the ability to innovate by make connections between different streams of information; and (3) to create value for others. Entrepreneurial thinking results in the development of a sound technical solution that addresses customer needs, is feasible from a business perspective, and has societal benefit.

It is difficult to develop the many professional skills needed by today's graduates within the framework of engineering programs that are crowded by technical requirements. A creative approach is to utilize online learning modules. There are several advantages to the online learning modules over the development of more traditional classroom content:

- A large number of students, ideally all engineering students, can be required to complete the modules thereby having broad impact

- The modules can be easily shared with other institutions for deployment

- The modules can be integrated into regular courses or serve as supplementary resources

- A "flipped class" instructional model can be used where classroom time is spent on practical applications and content is delivered outside of class time

- Students can learn the content asynchronously and fit the learning around their own schedules

\section{Learning Modules and Target Courses for Integration}

There are several concepts that students must learn in order to be entrepreneurially minded. To enable all engineering students in the Tagliatela College of Engineering (TCoE) at the University of New Haven (UNH) to learn these concepts, 18 interactive online learning modules will be developed and integrated into courses spanning all four years across all engineering and computer science disciplines. The titles of the online learning modules and the courses into 
Table 1: Online learning modules and target courses into which they will be integrated

\begin{tabular}{|c|c|}
\hline Online Learning Modules & Target Courses for Integration of Modules \\
\hline $\begin{array}{l}\text { 1. Generating new ideas based on societal needs and } \\
\text { business opportunities }\end{array}$ & \multirow{2}{*}{ Introduction to Engineering } \\
\hline $\begin{array}{l}\text { 2. Developing customer awareness and quickly testing } \\
\text { concepts through customer engagement* }\end{array}$ & \\
\hline 3. Thinking creatively to drive innovation & \multirow{2}{*}{ Project Planning and Development } \\
\hline 4. Learning from failure* & \\
\hline $\begin{array}{l}\text { 5. Establishing the cost of production or delivery of a } \\
\text { service, including scaling strategies* }\end{array}$ & Project Management and Engineering Economics \\
\hline 6. Determining market risks* & Applied Engineering Statistics \\
\hline 7. Designing innovatively under constraints & $\begin{array}{l}\text { Transport Operations II } \\
\text { Mechanics and Structures Lab } \\
\text { Software Project Analysis and Design } \\
\text { Junior Design Laboratory } \\
\text { Fundamentals of Mechanical Design } \\
\text { System Engineering Concepts and Design }\end{array}$ \\
\hline 8. Financing a business* & \multirow{5}{*}{$\begin{array}{l}\text { Business Fundamentals for Engineers (to be } \\
\text { developed) }\end{array}$} \\
\hline $\begin{array}{l}\text { 9. Developing a business plan that addresses } \\
\text { stakeholder interests, economics, market potential } \\
\text { and regulatory issues }\end{array}$ & \\
\hline 10. Marketing a product or service & \\
\hline 11. Adapting a business to a changing climate & \\
\hline 12. Delivering an elevator pitch & \\
\hline 13. Resolving difficult ethical issues & $\begin{array}{l}\text { Professional Engineering Seminar } \\
\text { Social \& Professional Issues in Computing } \\
\text { Professional and Ethical Practice }\end{array}$ \\
\hline $\begin{array}{l}\text { 14. Building, sustaining and leading effective teams and } \\
\text { establishing performance goals* }\end{array}$ & $\begin{array}{l}\text { Chemical Engineering Laboratory } \\
\text { Soil Mechanics Laboratory } \\
\text { Junior Design Laboratory } \\
\text { Thermo/Fluids Laboratory } \\
\text { System Engineering Design Process }\end{array}$ \\
\hline $\begin{array}{l}\text { 15. Building relationships with corporations and } \\
\text { communities }\end{array}$ & Mandatory internships \\
\hline 16. Applying systems thinking to complex problems* & \multirow{3}{*}{ Disciplinary Senior Design Courses } \\
\hline 17. Recruiting and servicing clients & \\
\hline 18. Defining and protecting intellectual property & \\
\hline
\end{tabular}

*Modules developed in Fall 2014

which they will be integrated are specified in Table 1. Modules 1-6 will be integrated into core courses that are common to many disciplines. Modules 8-12 will be integrated into a new Business Fundamentals for Engineers course that will be developed. Modules 7 and 13-18 will be integrated into junior/senior courses specific to each discipline. Seven modules $(2,4-6,8,14$ and 16) were developed in Fall 2014. The remaining modules will be developed in stages over the next two years. Five of the seven modules developed so far are being deployed in Spring 2015, and additional modules will be deployed progressively. All modules will be fully deployed by Spring 2017 . 
Students in all engineering majors will complete 13 of the online modules through required courses. Only students who take the elective Business Fundamentals for Engineers course will complete modules 8-12. Each module will take 5-9 hours to complete. The modules are designed to standalone and do not have any particular prerequisite structure.

\section{Development and Deployment of Modules and Faculty Training}

Requests for proposals are issued to faculty at UNH, those at other institutions and industry consultants who have relationships with the TCoE for the development of the online learning modules. Potential developers submit their proposals using a concise form. The authors and a program director of the granting agency review the proposals received to select a developer for each module. The developers are required to undergo formal training on how to design and construct online learning modules that are highly interactive and of high quality. The Office of eLearning at UNH provides the necessary training through a 3-week online course to both UNH faculty and to faculty at other institutions. The modules are designed for course instructors to deploy in an asynchronous mode. Exercises and assessment of student learning are included in each online module. The online modules will be integrated into the courses identified in Table 1 and students will be required to complete them as part of each course. The modules do increase the workload for students, but because they are completed outside of class times, the time available for instructors to cover technical content is not reduced.

Faculty deploying the online modules into courses are charged with developing contextual material in their courses that relate to the concepts covered in the modules so as to further deepen student learning. However, faculty need help in order to do this effectively and consistently across the many courses listed in Table 1, especially because many of them are not content experts, and hence an entrepreneurially oriented consultant assists faculty. The tasks of the consultant include:

- Developing detailed learning outcomes for each of the online modules

- Helping faculty develop the contextual material in each of the target courses

- Playing a leading role in summer faculty development workshops

- Working closely with the authors with evidence collection and assessment

One-day training workshops are held each year for faculty who deploy online modules in their courses. During these workshops faculty:

1. Learn about the entrepreneurial mindset through a videoconference presentation made by a program director from the funding agency.

2. Engage in an entrepreneurially minded learning activity conducted by the authors.

3. Receive instruction from the Office of eLearning on how to use the online modules effectively within their course.

4. Learn from the Office of eLearning on how to access the online modules from within their course Blackboard sites and how to obtain the assessment results from the modules for inclusion in their course grades.

5. Receive instruction from the Office of eLearning on how to manage discussions related to the open-ended question included within each online module.

6. Be introduced via videoconference to the consultant who will visit campus to help them develop the contextual class exercises or projects. 
Faculty participation in the workshop will be staggered with those who will be engaged during the first year being trained first, and more and more faculty teaching courses that deploy the online learning modules being trained in later years.

\section{Module Architecture, Format and Instructor Resources}

The online modules are developed using Trivantis's Lectora platform. ${ }^{4}$ The developed modules are integrated into the Blackboard Learning Management System (LMS) used at UNH. Modules are also converted to SCORM (Sharable Content Object Reference Model) ${ }^{5}$ objects that may be downloaded and integrated to any other LMS system.

Each online module is designed to be independent and stand-alone, although to be most effective it should be integrated into a course or activity that can provide meaningful engineering contexts. Each module will take 5-9 hours to complete, depending on the content and the learning speed of the student and contains readings, short videos and interactive self-assessment exercises. A test that can be taken only once by each student is included at the end of each module and the test score will be included in assigning the student's grade for the course that includes the module.

An Instructor's Guide is available for each module. This guide provides integration strategies, the learning outcomes, a suggested open-ended class discussion question, and either questions that can be embedded into the final examination for the course or activities that can be included within a course project. Additional reading resources and links to relevant videos are also provided.

The open-ended discussion can be conducted in class, online or a combination of both. In the discussion question shown in Appendix A for the Cost of Production module, the instructor poses an open-ended problem with a clearly stated learning objective. Students are required to respond with an initial post that outlines their planning solution in response to the problem posted. Each student will review the initial responses from peers and reflect on their solution to the problem. Finally, everyone must respond to the posts and comment on at least two other posts in the follow-up discussion. Students are requested to follow netiquette protocol and extend an observation or comment on an insight they did not consider.

\section{Description of Select Modules}

The online modules target courses that span from freshman to senior year of engineering programs. One module at each level is described below.

\section{Developing Customer Awareness and Quickly Testing Concepts through Customer Engagement}

The module Developing Customer Awareness and Quickly Testing Concepts through Customer Engagement provides students with an overview of methods used for bringing innovation to market rapidly through customer engagement. This module will help students develop skills in investigating a market, and testing concepts quickly via customer engagement.

The module consists of three lessons followed by a summary assessment of the entire module. Lesson 1 explores how innovation is brought to market rapidly and effectively through a reproducible process centered upon the customer. Students are introduced to successive refinement using analogies of evolution and USAF Colonel John Boyd's OODA loop (Observe, Orient, Decide, Act). The bilateral nature of customer engagement is first considered in Lesson 2, before examining customer awareness methods including case studies drawn from classical marketing, customer satisfaction measurement techniques, customer advisory boards 
and web-based and social media driven mechanisms. Lesson 3 then surveys rapid concept testing by way of customer engagement beginning with a brief overview of classical product marketing driven R\&D followed by modern rapid prototyping, Agile Development, and the Maker movement.

Each lesson engages the student using a combination of videos, stories, and case studies. Through thought-provoking articles and relevant case studies, students are challenged to reflect on how technology is changing customer engagement such as the case study describing Volkswagen's social media campaign on Building the People's Car in China. Students have the option to either listen or read the mini-lectures embedded throughout the lessons.

Concepts learned in the module pertaining to customer awareness and engagement is reinforced in each lesson using a series of 2-3 multiple-choice questions often following readings or mini-lectures. The summary assessment consists of both factual questions and questions that require students to reflect and draw conclusions from what they learned. Illustrated in Figures 1 and 2 are the factual and higher order questions pertaining to the impact of cell phones on customer engagement.

Upon completing the module, students will be able to:

- Compare the process of testing concepts through customer engagement driven by customer awareness to examples of successful successive refinement including evolution of species and USAF Colonel John Boyd's OODA loop;

- Analyze a proposed customer awareness technique relative to a stated product/service and market environment;

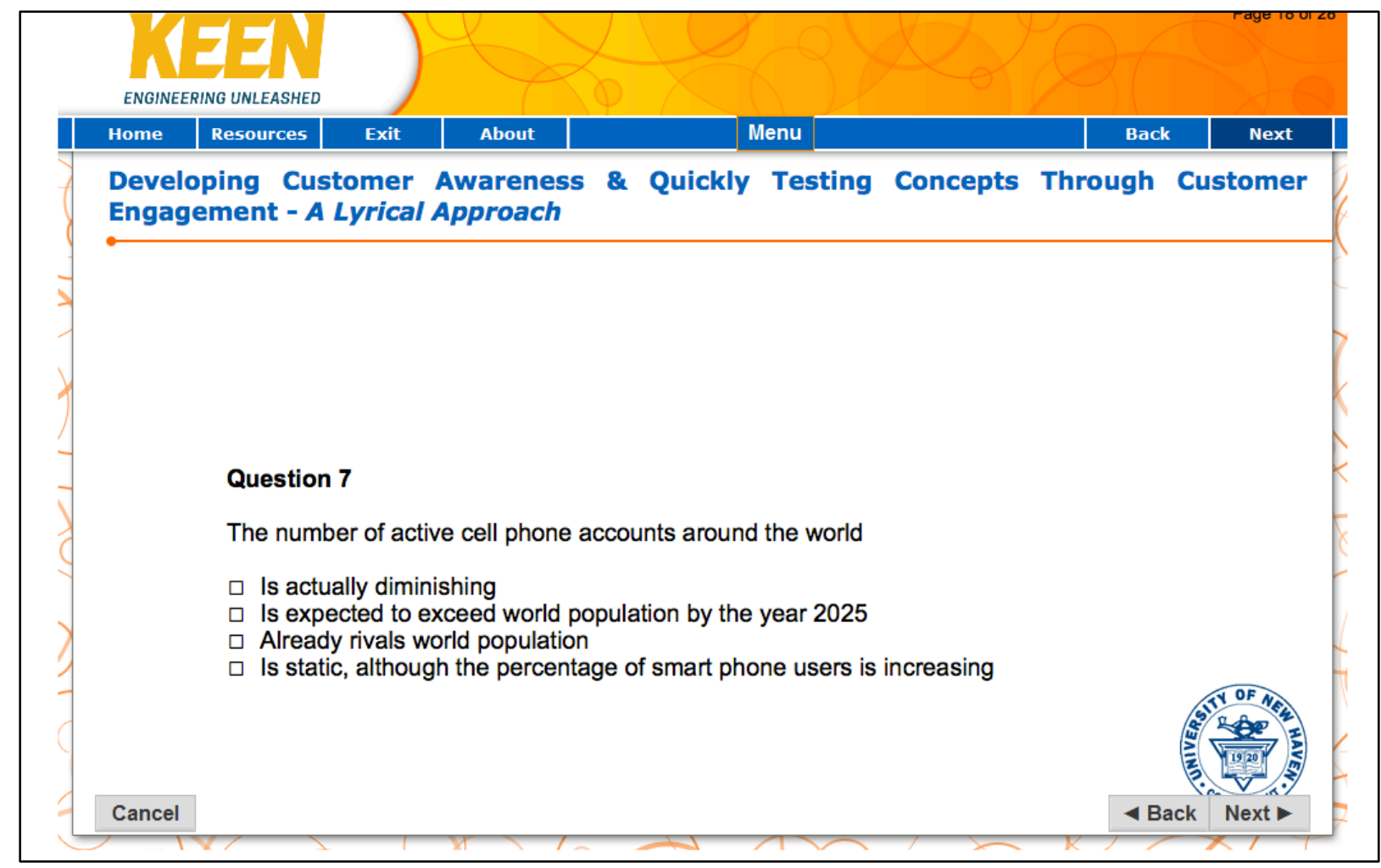

Figure 1. Factual question on cell phones 


\section{Question 8}

Today, the number of active cell phone accounts rivals global population and the majority of internet usage worldwide occurs on mobile devices. This surely creates opportunity for bilateral engagement between customer and vendor. Argue for the greatest attendant risk of this mindboggling connectivity.

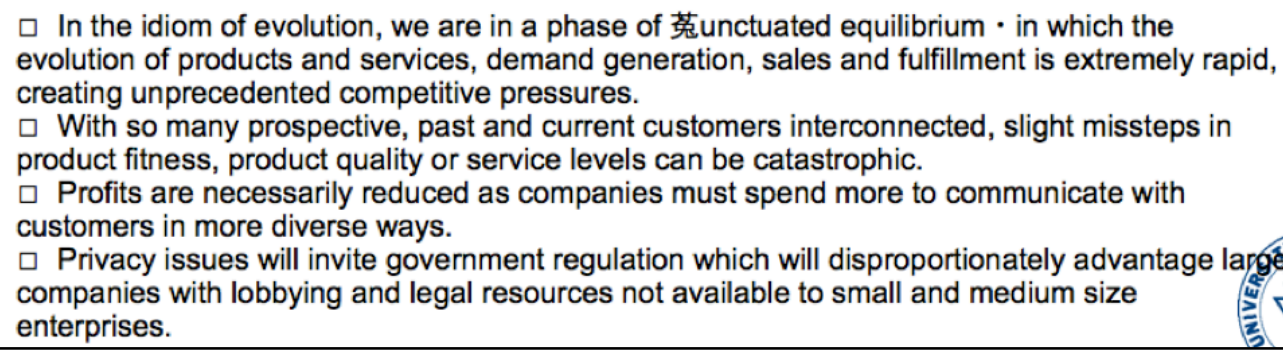

Figure 2. Reflective/higher order question pertaining to cell phones

- Make inferences drawn from a published article about the Maker movement on the democratization of innovation.

The module Developing Customer Awareness and Quickly Testing Concepts through Customer Engagement is being piloted in a section of the EASC 1107: Introduction to Engineering course during the spring 2015 semester. Students will be assigned the module two weeks prior to introducing the final team project. The instructor will facilitate discussion between the students as they are completing the module by posting a discussion question pertaining to customer engagement. Students will be required to respond with an initial post first, before reviewing and commenting on at least two of their peers' responses. Customer engagement methods will be incorporated in the final team project.

\section{Cost of Production}

The online module entitled Cost of Production focuses on establishing the cost of production or delivery of services including scaling strategies. This module introduces students to concepts of production costs, market structures and internet markets. Using this interactive learning module, the students examine three real-life bicycle companies operating in a competitive market place (see Figure 3). Each company has a unique strategy: a different approach designing, differentiating, building and supplying bicycles to their target markets. At the end of the module, the students are asked to play the role of a bicycle designer and compete against one or more of the companies they learn about in the module.

After completing the online modules, using the production and marketing strategies of the three different bicycle companies as examples, students will be able to:

- Recognize how design impacts costs of products;

- Examine volume constraint and perform what if analysis for scaling up volume; and

- Appraise the decision to add labor or capital. 


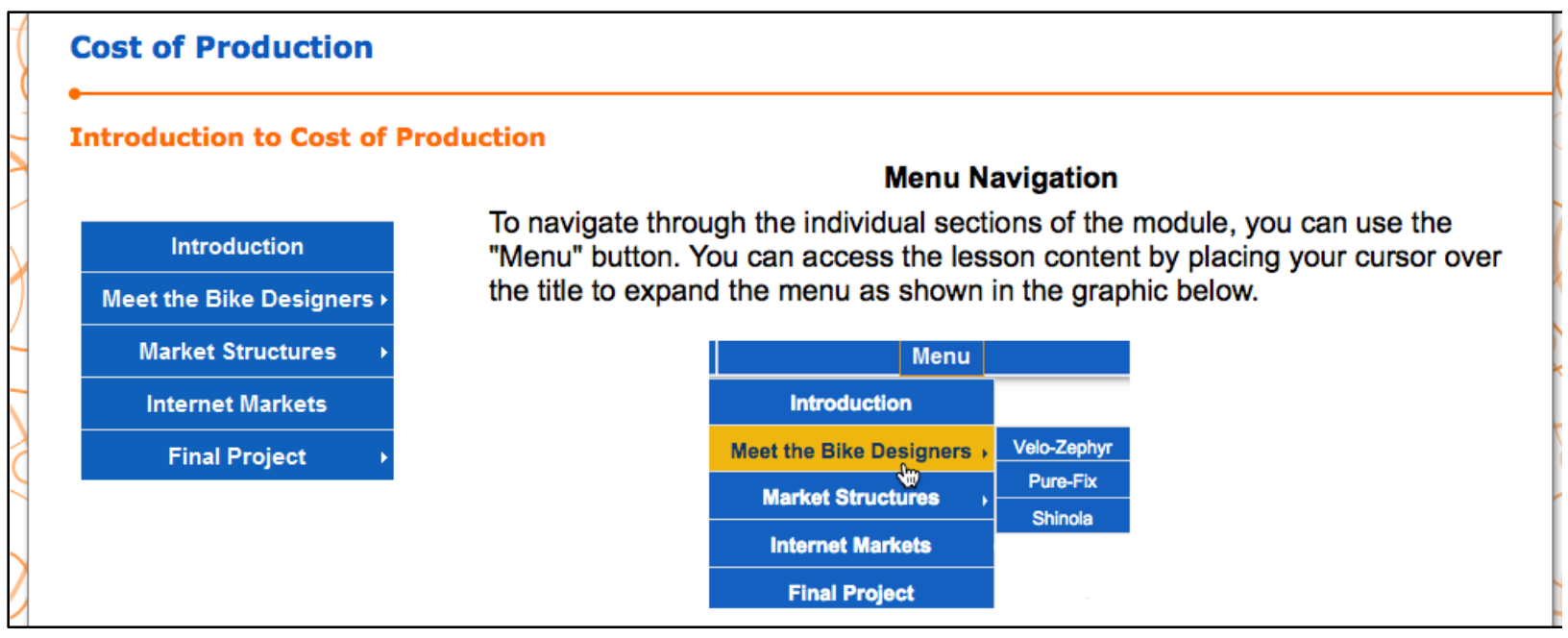

Figure 3. Cost of Production - Module content

This module will help students develop skills in identifying an opportunity, investigating the market, creating a preliminary business model, and evaluating technical feasibility, customer value, societal benefits, and economic viability. These skills are critical for the development of an entrepreneurial mindset. The overarching learning outcomes targeting entrepreneurial thinking in the Cost of production module are to: (1) evaluate technical feasibility and economic drivers; (2) examine societal and individual needs; (3) convey engineering solutions in economic terms; and (4) identify personal passions and a plan for professional development.

The material is delivered through a combination of text, video, and graphics, and is presented in an engaging, interactive format. Figure 4 shows a sample module page. The module also contains self-assessment exercises as well as a graded final project presented at the end. Samples of these assessment activities are shown in Figures 5 and 6.

\section{Lesson 2: Market Structures}

Click the arrow to play this video to gain an understanding of the Competitive market structure.

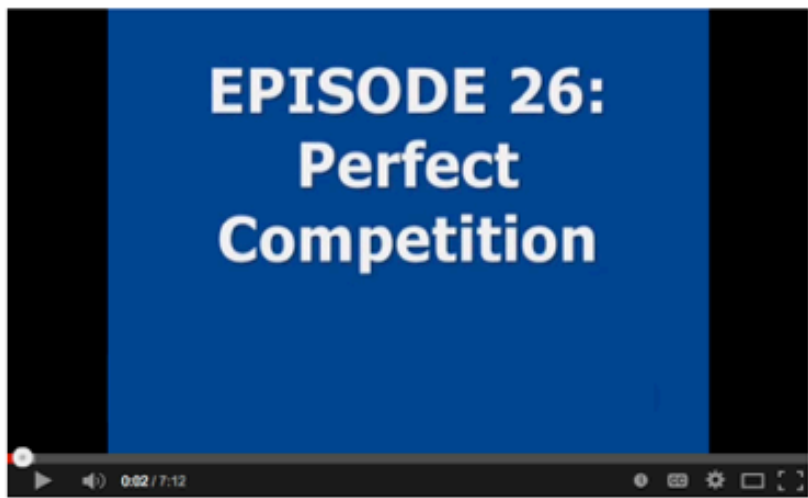

The "Competition" video by Dr. Mary J. McGlasson is licensed under a Creative Commons Attribution-NonCommercial-NoDerivs 3.0 Unported

\section{Notes:}

Click here to see the written highlights of this video. You may want to do this so you can print this and refer to it later as we review the case studies.

On the next few screens, we will see how monopoly and oligopoly compare to a competitive market.

Figure 4. Cost of Production - Sample page 


\section{Lesson 1: Meet the Bike Designers: Steve Herzfeld - Velo-Zephyr \\ What kind of people do you think would buy the bikes Steven makes? \\ Racers \\ People who want a high performance bike \\ College students \\ People who want an inexpensive bike}

Figure 5. Cost of Production - Multiple choice question

Lesson 1: Meet the Bike Designers: Zach Schau - Pure Fix

From what you have learned so far, do you think Pure Fix might has a sustainable model to grow their business? Why?

Figure 6. Cost of Production - Reflection question

Multiple-choice self-assessment questions have built in feedback, which allow students to evaluate their understanding of the material. Short reflection questions allow students to selfassess their ability to communicate what they learned. The final challenge is a mini project, which allows students to demonstrate their knowledge by constructing cost model(s) using material learned in the module.

The Cost of Production module will be deployed in the second year engineering course Project Management and Engineering Economics through multiple channels. The existing class project will be modified to align with concepts covered in the module. An online discussion forum will be used as a group exercise, which will provide students a platform to express their understanding and share reflections and thoughts on the content of the module. Furthermore, follow-up in-class discussions will be conducted to reinforce students' understanding of key concepts.

\section{Building, Sustaining and leading Effective Teams and Establishing Performance Goals}

The Building, Sustaining and leading Effective Teams and Establishing Performance Goals module provides students with the necessary guidance to assess team dynamics and performance. After completing the module, students will have a better understanding of their role in an effective team, be prepared to evaluate their role in promoting team goals and be able to establish performance measures both individually and for the team.

Three lessons are included in the module to help students build an effective understanding of teams: Functioning of Teams, Individual Perceptions, and Team Performance. Lessons include a well-structured set of text, audio and video guidance on the lesson topics, with a brief focused content that supports the lessons with authoritative references to articles or external websites. Each lesson has brief quizzes and reflection questions designed to reinforce critical content while the end-of-module assessment tool provides good overall feedback on student understanding of the lessons. Students can navigate the lessons easily with a simple menu system 
to reinforce topics that might require additional review based on the assessment feedback and retake the assessment to improve their scores. An estimated 9 hours is needed for a student to successfully complete this module.

The first lesson, Functions of Teams, starts with key articles on "The Critical Role of Teams" by Ken Blanchard ${ }^{6}$ and "Work Groups and Teams in Organizations" by Kozlowski and Bell $^{7}$ followed by reflections and brief assessment questions that reinforce content. Tuckman's four stages of team development: Forming, Storming, Norming, and Performing, ${ }^{8}$ follow taking the student through the different stages of team development with video and interactive graphics, keeping the presentation both interactive and interesting. An example of an interactive exercise from the lesson is shown in Figure 7. The role of consensus and compromise round out the lesson with a set of personal reflection questions and brief interactive scenarios to help personalize the understanding of consensus and compromise as well as tips for finding consensus. Ten self-assessment questions that provide immediate feedback wrap up the lesson, reinforcing understanding more than memorization of the lesson content delivered.

The second lesson, Individual Perceptions, gives the student a chance to examine their own personality type and individual preferences so they can better understand the factors that influence actions and decision making in a team. The lesson also links back to the first lesson with a piece on reaching consensus based on different viewpoints. The Myers Briggs Type Indicator $^{\circledR}(\mathrm{MBTI})^{9}$ is used to establish the sixteen different personality types shown in Figure 8 using a video presentation of the four key facets of personality and links to authoritative references from Truity Pschometrics LLC and Neris Analytics Limited to help explain these types and how they might best interact in a team setting. Given the often surprising results from these MBTI tests, the lesson wisely focuses on the value and importance of the student to team performance encouraging students to reflect at length on the personality test. Given the varied personality types, the addition of a section on the Objective, Reflective, Interpretive, Decisional (ORID) process for reaching consensus is well placed as the final element in the lesson.

The third and final lesson of the module is Team Performance. Bringing focus to wellknown effective teams and introducing standard team performance tools such as team charters and performance plans, the lesson wraps up the team-based module with the crucial questions of how best to measure team performance. A sample six-element team performance plan - mission,

Building, Sustaining \& Leading Effective Teams

Lesson 1: Stages of Team Development

During the Forming stage, group activities are more about organizing the group effort rather than contributing to project work. Behaviors include:

- Exchange of information

- Attempt to figure out the assignment or task

- Attempt to agree upon acceptable etiquette

- Complaints about the tasks or assignment

Click on \#2 or the Next button to proceed.

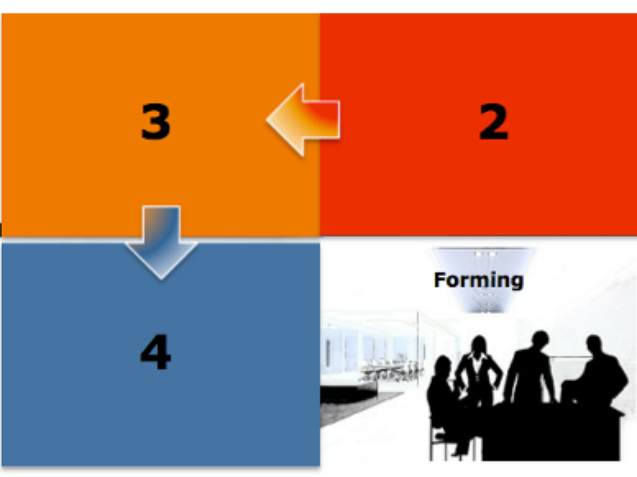

Tuckman's Stages of Team Development

Figure 7. Example of modules interaction from Lesson 1 
Building, Sustaining \& Leading Effective Teams

\begin{abstract}
Lesson 2: Individual Perceptions Now that you know a little more about yourself, let's see how this might help you to work in a team situation. One thing that is often helpful is for each person in the group to share his or her personality type. If you know where another person is coming from, it is often easier to communicate with him or her, which leads to more effective team interaction. This chart show a summary of the various personality types. Take a look and see how other people may have scored on their personality tests. You may want to print this to answer the questions on the following screens.
\end{abstract}

\begin{tabular}{|c|c|c|c|}
\hline $\begin{array}{c}\text { INTJ } \\
\text { Imaginative and strategic } \\
\text { thinkers, with a plan for } \\
\text { everything }\end{array}$ & $\begin{array}{c}\text { INTP } \\
\text { Innovative inventors with } \\
\text { an unquenchable thirst } \\
\text { for knowledge }\end{array}$ & $\begin{array}{c}\text { ENTJ } \\
\text { Bold, imaginative and strong } \\
\text { willed leaders, always finding } \\
\text { a way or making one. }\end{array}$ & $\begin{array}{c}\text { ENTP } \\
\text { Smart and curious thinkers } \\
\text { who cannot resist an } \\
\text { intellectual challenge }\end{array}$ \\
\hline $\begin{array}{c}\text { INFJ } \\
\text { Quiet and mystical, yet } \\
\text { very inspirng and tireless } \\
\text { idealists }\end{array}$ & $\begin{array}{c}\text { INFP } \\
\text { Poetic, kind and altruistic } \\
\text { people, always eager to } \\
\text { help a good cause }\end{array}$ & $\begin{array}{c}\text { ENFJ } \\
\text { Charismatic and inspiring } \\
\text { leaders, able to mesmerize } \\
\text { their listeners }\end{array}$ & $\begin{array}{c}\text { ENFP } \\
\text { Enthusiastic, creative and } \\
\text { sociable free spirits who can } \\
\text { always find a reason to smile. }\end{array}$ \\
\hline $\begin{array}{c}\text { ISTJ } \\
\text { Practical and fact minded, } \\
\text { individuals whose } \\
\text { reliability cannot be } \\
\text { doubted. }\end{array}$ & $\begin{array}{c}\text { ISFJ } \\
\text { Very dedicated and } \\
\text { warm protectors, always } \\
\text { ready to defend their } \\
\text { loved ones. }\end{array}$ & $\begin{array}{c}\text { ESTJ } \\
\text { Excellent administrators, } \\
\text { unsurpassed at managing } \\
\text { things - or people. }\end{array}$ & $\begin{array}{c}\text { ESFJ } \\
\text { Extraordinarily caring, social } \\
\text { and popular people, always } \\
\text { eager to help. }\end{array}$ \\
\hline $\begin{array}{c}\text { ISTP } \\
\text { Bold and practical } \\
\text { experimenters, masters of } \\
\text { all kinds of tools. }\end{array}$ & $\begin{array}{c}\text { ISFP } \\
\text { Flexible and charming } \\
\text { artists, always ready to } \\
\text { explore and experience } \\
\text { something new. }\end{array}$ & $\begin{array}{c}\text { ESTP } \\
\text { Smart, energetic and very } \\
\text { perceptive people, who truly } \\
\text { enjoy living on the edge. }\end{array}$ & \begin{tabular}{|c|} 
ESFP \\
Spontaneous, energetic and \\
enthusiastic entertainers - life \\
is never boring around them
\end{tabular} \\
\hline \multicolumn{4}{|c|}{ Click on the table above to see it in a larger format. } \\
\hline
\end{tabular}

Figure 8. Lesson 2 module listing 16 Myers-Briggs personality types

team dynamics, project planning, execution, assessment, performance review - is presented as an example with brief reflection questions and quizzes to help student understanding of each portion of the six steps in the sample performance plan. A ten-question quiz on the lesson provides a final check of student mastery of the essential concepts. While briefer than the other two lessons, the intent is that students taking this module are taking a class (or classes) that require a substantial team project activity and to help focus the student's thoughts and attention on the how best to implement a team performance plan for that impending team project.

After completing the three lessons in the module: Building, Sustaining \& Leading Effective Teams, students should be able to:

- Recognize the team life-cycle model, identify success factors at each stage of the team development process that influence productivity, and differentiate between consensus and compromise;

- Examine individual preferences found in a personality comparison instrument, identify factors that influence actions and decision making tied to that personality, and recognize the four different viewpoints used to reach consensus; and

- Relate the importance of both team and individual performance to overall team objectives and design a six-step performance plan.

This module is being piloted in the junior level laboratory courses in mechanical and civil engineering in the spring 2015 semester. The two laboratory courses, Mechanics Laboratory and Structures Laboratory have a well-established interdisciplinary team project activity that helps to address ABET EAC General Criteria 3. (d) an ability to function on multidisciplinary teams. Experience with the joint ME/CE design teams has shown the difficulty in effectively meshing student teams even with closely related disciplines. The junior level courses provide an early intervention to help prepare students for the industry-based full year senior design capstone projects but with less at stake compared to the senior design courses. 
The pilot classes will complete the Building, Sustaining \& Leading Effective Teams module prior to the start of the major design experience and formation of multidisciplinary teams.

Faculty will establish online and in-class forums to discuss the completed module and then have students implement a six-step team performance plan for the combined ME/CE design project. The performance plan with individual and team assessment features will be a portion of their team project grade for the class and hopefully provide some necessary and essential feedback on building, sustaining and leading effective teams.

\section{Applying Systems Thinking to Solve Complex Problems}

The problems encountered in engineering practice are often ill defined and highly complex. The module Applying Systems Thinking to Solve Complex Problems is designed to assist students in tackling such problems. The module demonstrates how to simplify problems by using common tools such as function mapping, decomposition and heuristic rules.

The module is broken down into five lessons. To ensure a basic understanding of the terminology independent of the user's background, the module starts off with a set of interactive pre-assessment questions, one of which is shown in Figure 9, followed by Lessons 1 and 2 that discuss the various foundational concepts and key principles addressed in the pre-assessment. Four approaches for architecture development are provided in Lesson 3, while Lesson 4 goes in depth into heuristic descriptions of a system (see Figure 10). The concepts of verification and validation, that are key to the system engineering process, are presented in Lesson 5.

The module engages students by having them watch short videos, respond to open ended questions and reflections, and use examples grounded on experience (e.g., a bicycle) in order to clarify difficult concepts such as the systems engineering "V". Self-assessment exercises are scattered throughout the module and provide an opportunity to emphasize concepts and correct misconceptions.

The module concludes by having the user (student) apply the concepts to address a simplified complex problem, that is, to role play being on a team that has been hired to design a system that helps study the effects of climate change by studying the tops of trees.

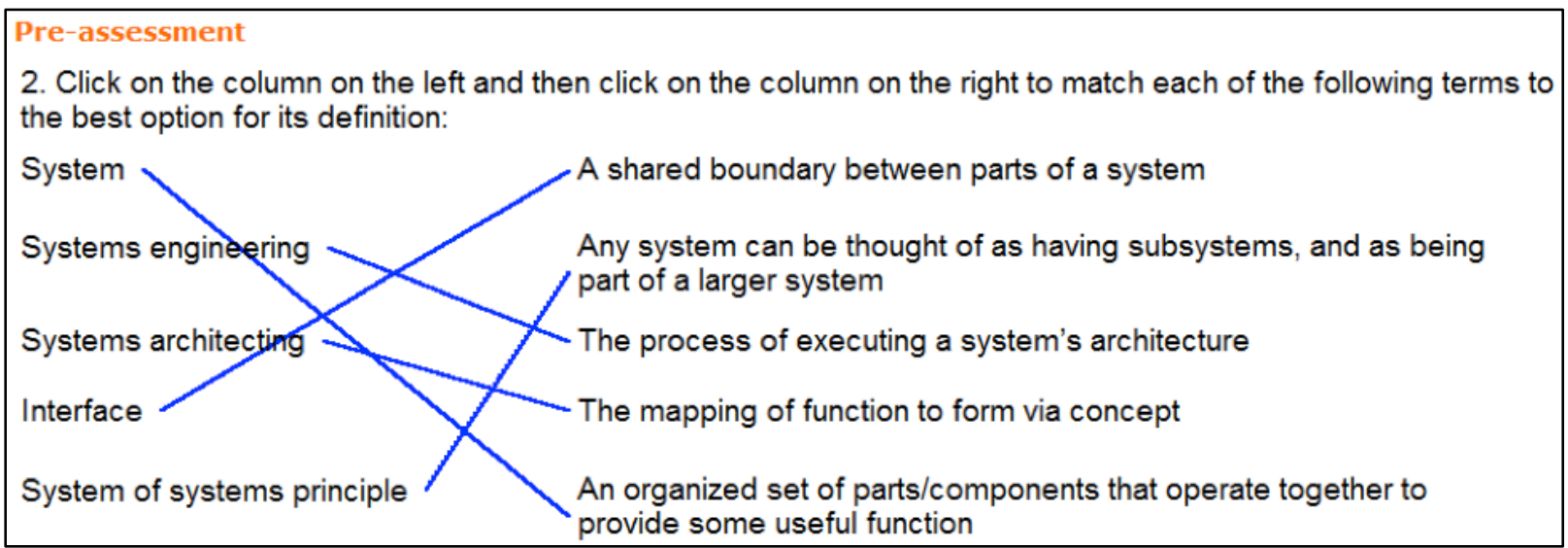

Figure 9. Applying Systems Thinking - A pre-assessment question 


\section{Views of Systems}

In addition to the types of systems, heuristics enable us to consider the systems from various views.

For each view of the system, a brief description is provided for that view, as well as some guidelines to use when considering that view of the system.

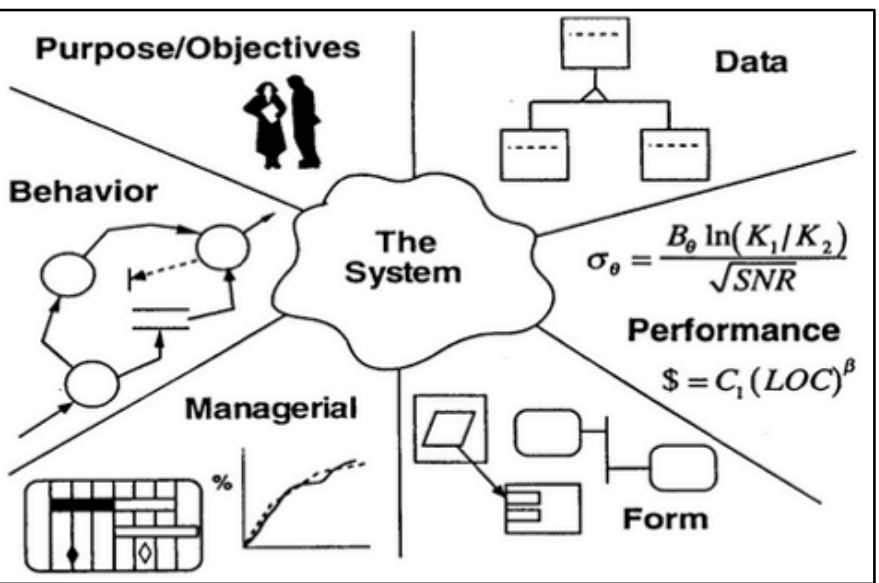

Figure 10. Applying Systems Thinking - View of systems

Upon completion of the modules, students will be able to:

- Define a system, systems architecture, and system engineering

- Decompose a system hierarchy to at least four levels

- Define any system from various perspectives, including technical feasibility, value, risk, and societal impact

- Describe four methods of developing a system architecture

- Apply the heuristic architecting method to develop a system architecture

- Develop a functional decomposition for a system using the material/signal/energy approach

- Apply the systems engineering " $V$ " to implement a complex system

In Fall 2015 the Applying Systems Thinking to Solve Complex Problems module will be deployed in senior design courses within all engineering disciplines. Students will be asked to reflect how systems thinking could impact the work they are carrying out and asked to place their work in context of the system engineering process.

\section{Assessment}

Three types of assessment, knowledge acquisition, behavior/mindset growth, and solicitation of student feedback on the effectiveness and relevance of the modules will be conducted to evaluate the success of deploying the online modules in engineering courses.

Assessment of knowledge acquisition related to entrepreneurial thinking will be based on student performance in: (1) the multiple-choice test built into each online module; (2) a class assignment designed to reinforce concepts learned in the module; and (3) final examination questions related to the content in the modules.

Instructors will develop at least one class assignment to reinforce concepts learned through the online modules. This may be a homework problem or a project. An external consultant familiar with entrepreneurial thinking will assist faculty members develop the assignment.

The content experts who develop the online modules also provide sample questions that can be used in the final exams of the courses into which modules are integrated. Instructors are expected to have at least one question related to the online modules integrated in their courses in 
the final examination. Some sample final exam questions for the Building, Sustaining and Leading Effective Teams module are given in Appendix B.

Student behavior/mindset growth related to entrepreneurial thinking will be assessed through the following two types of survey instruments and studies:

1. Program-Level Assessment: The baseline survey shown in Appendix $\mathrm{C}$ will be administered to entering freshmen before they have completed any online module. Psychological measurement theory suggests that lengthy questionnaires can lead to low response rates and distorted responses due to fatigue. ${ }^{10,11}$ Therefore, the survey was designed to be concise with 37 items. Students' general entrepreneurial mindset such as the intellectual and exploratory curiosity levels, interests and experiences in entrepreneurship, career goals, etc. will be measured through 12 items. The learning outcomes of the 18 online modules will be measured through 25 items, with one or at most two questions related to each module.

The baseline survey will be administered a second time when students complete their BS programs. All students will have taken at least 13 of the 18 online modules by the time they graduate. Some students will have taken all 18 modules. The survey results at the beginning and end of each student's program will be compared to assess how the totality of the proposed online modules improve student growth in general entrepreneurial mindset/behavior. Students who take the Business Fundamentals for Engineers class and thereby complete all 18 modules will be grouped separately in the analysis.

2. Course-Level Assessment: In each course into which a module in integrated, students will also be administered a module-specific survey at the beginning of the course before the module is deployed. This will serve as a pre-assessment of student awareness of the entrepreneurial characteristics that students are expected to develop after completing the module and reinforcement assignment. The module-specific surveys for the Developing Customer Awareness and Learning from Failure modules are shown in Appendices D and $\mathrm{E}$.

Students will be administered the same module-specific survey as a post-assessment at the end of a course in which a module is integrated. The survey results from the beginning and end of each course, together with each module's content assessment results, will indicate how well students learn the content of each module.

The third type of assessment will be the collection of student feedback regarding each online module. Specific questions related to the effectiveness and relevance of the online module integrated into a course will be included in the regular end of semester course evaluation.

Results of the three types of assessments will be used to improve the structure, content and integration of each online module.

\section{Conclusions}

The development and implementation of online modules designed to promote entrepreneurial thinking of engineering students is described. When complete in December 2016, a total of 18 online modules will have been developed. The modules will be integrated into existing engineering courses and a new Business Fundamentals for Engineers course. Approaches to assess student learning of entrepreneurial thinking through deployment of the modules and course assignments designed to reinforce the content of the modules are described. Assessment of learning will be conducted at both the course and program level. 


\section{Acknowledgement}

The Kern Family Foundation funded the development and implementation of the online modules in the Tagliatela College of Engineering at the University of New Haven. We are thankful to Karen Wilken, a program manager at the foundation, for her interaction and feedback throughout the project.

\section{References}

1. Duval-Couetil, N., Reed-Rhoads, T., and Haghighi, S. (2012). "Engineering students and entrepreneurship education: Involvement, attitudes and outcomes." International Journal of Engineering Education, 28, 425-435.

2. Sander, E. (2011). "Engineering entrepreneurship: Learning by doing." Proceedings, 118th ASEE Annual Conference and Exposition, American Society for Engineering Education, Vancouver, BC, Canada.

3. Beaury, R., Boyer, P., and Kisenwether, E. (2010). "Using live cases in problem-based entrepreneurship learning." NCIIA 14th Annual Meeting Publications.

4. Trivantis. "Lectora." $<$ http://lectora.com/inspire-e-learning-software/whats-new $>$, Retrieved January 30, 2015.

5. Advanced Distributed Learning, "SCORM." < http://www.adlnet.gov/scorm/>, Retrieved January 30, 2015.

6. Ken Blanchard Companies, "The critical role of teams."

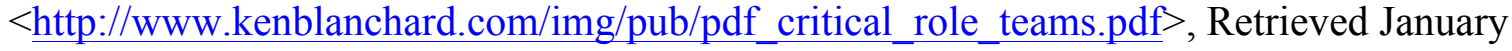
$30,2015$.

7. Kozlowski, S. W., and Bell, B. S. (2001). "Work groups and teams in organizations." Retrieved January 30, 2015, from Cornell University, ILR School site: $<$ http://digitalcommons.ilr.cornell.edu/articles/389/>.

8. Tuckman, B. (1965). "Developmental sequence in small groups." Psychological Bulletin, 63(6): 384-99.

9. Myers, I. B., and Myers, P. B. (1995). Gifts differing: Understanding personality type. Mountain View,CA: Davies-Black Publishing.

10. Suskie, L.A. (1996). Questionnaire survey research: What works, 2nd edition. Tallahassee, FL: Association for Institutional Research.

11. Herzog, A. R., and Bachman, J. G. (1981). "Effects of questionnaire length on response quality." The Public Opinion Quarterly, 45(4), 549-559. 


\title{
Appendix A - Sample Class Discussion Question
}

\section{(From Instructor's Manual for Cost of Production module)}

\author{
Open-Ended Problem: Develop a Business Plan
}

Learning Objective:

- Calculate the total cost to produce a bicycle at an affordable price.

Teaching Note: This discussion thread can be offered near the end of the module or after the module is completed as a class assignment. You can use this discussion as a group exercise in class (with modification) or use a learning management system to complete it online.

You and several friends discuss that you are always late for class and determine that riding a bike to class would make that problem go away. You and your friends visit the local bike shop and determine that the bikes cost more than you thought. Develop a plan to sell bikes to your fellow students at an affordable price. In your plan answer the following questions:

1. What are the possible options available to you and your fellow entrepreneurs?

2. How much funding will you need?

3. How would you determine your needs?

4. What are some of the options for raising funds?

5. How will you determine the need for additional funding after you launch the business?

Instructions:

Initial Post

Create a thread (online discussion option) that outlines your planning process in response to the questions posed.

Follow up Discussion

After reviewing the responses of your peers, consider whether their planning processes will be successful in launching a business.

Respond to Posts

Review and comment on at least two other posts in the follow up discussion. Follow netiquette protocol and extend off (add to) an observation and or comment on an insight you had not considered.

Deadline:

Ideally (in an online environment), students will have a few days between the initial post and responses. 


\section{Appendix B - Sample Final Exam Question}

(Fill-in-the Blank and Multiple Choice Questions from Instructor's Manual for Building, Sustaining, and Leading Effective Teams and Establishing Performance Goals module)

Fill-in-the Blank

1) Understanding your personal KSAs and ambitions allows you to be a high performing member of the team. Being aware of one another's personality types can improve team functionality. aligning individual and team performance goals.

[Answer: Shared expectations]

2) The following are steps in . [Answer: Project

Planning] can positively impact team performance by

a. Review the project assignment (mission) for any specific measures and deadlines.

b. Break down the major goals into smaller deliverables.

c. Self-assign deliverables

d. Set up a weekly meeting schedule that includes time for individuals to report on their progress and receive feedback.

3) ORID is an acronym for four different viewpoints or ways to address a problem or issue. The ORID process uses question prompts to explore problems from these four different lenses. They are [Answer: Objective, Reflective, Interpretative, Decisional]

4) The following considerations make up a checklist to help you think about your role with the . [Answer: team]

- What do you learn from the team?

- What are your objectives from this project?

- What is it that you want to gain from participating in this project?

- What resources will it take to help you be successful?

- How to know when you have met your mark?

Multiple Choice

5) What factor(s) do not improve the probability that a team will be more productive? Choose all that apply.

a. Team members have an understanding of the team life-cycle model

b. At least one member of the team helps the group work toward finding a consensus

c. Taking time to discuss feelings is a waste of time. [ANSWER]

d. It is not enough to just want an outcome; you have to be willing to work for it. 


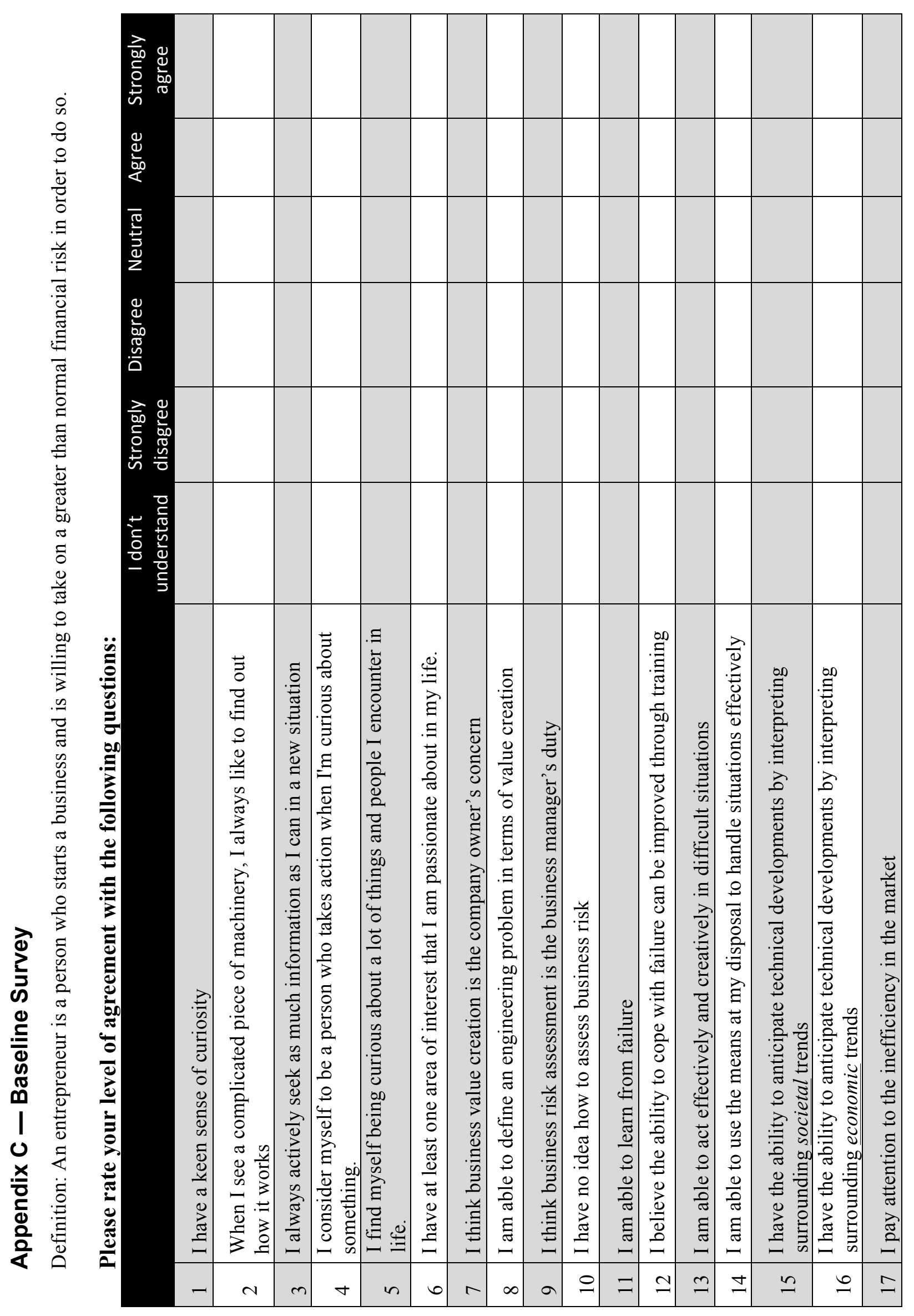

0
$\mathbb{0}$
0
0
$N$
0
$\stackrel{0}{0}$
$\vdots$
$\infty$ 


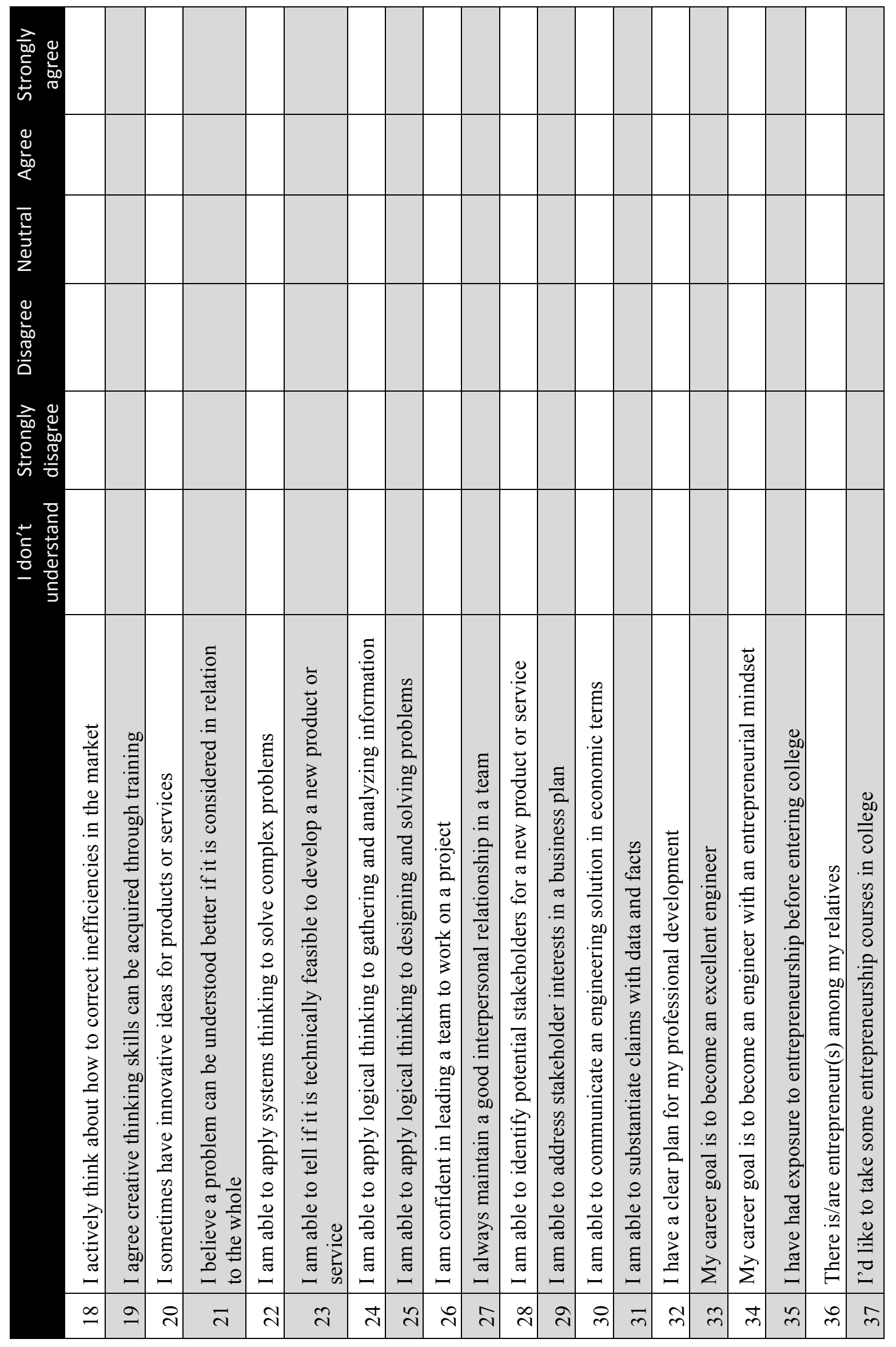

$\mathbb{D}$
$\mathbb{0}$
0
$\widetilde{O}$
$\stackrel{0}{0}$
$\stackrel{0}{0}$
$\overrightarrow{0}$ 


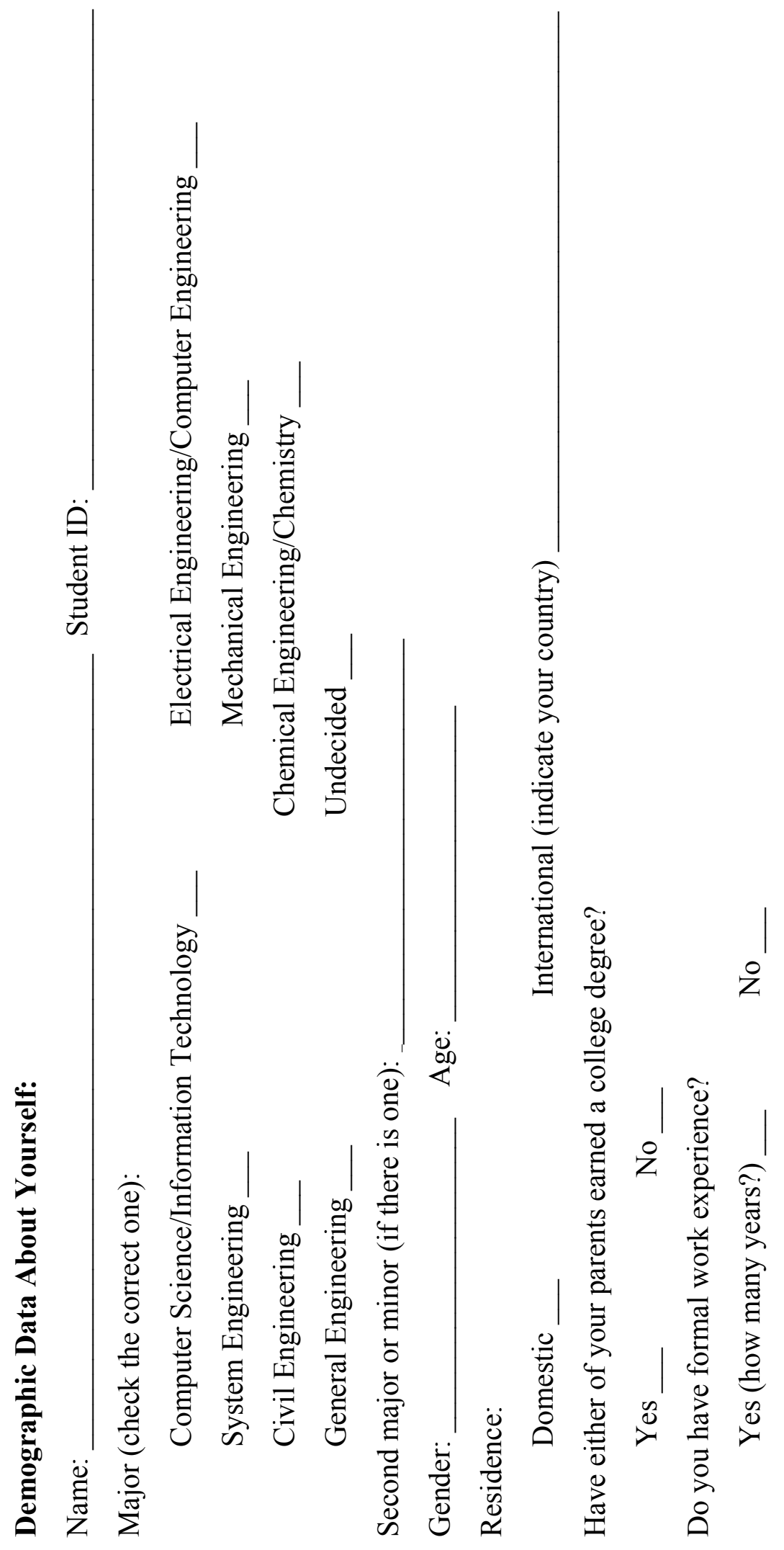




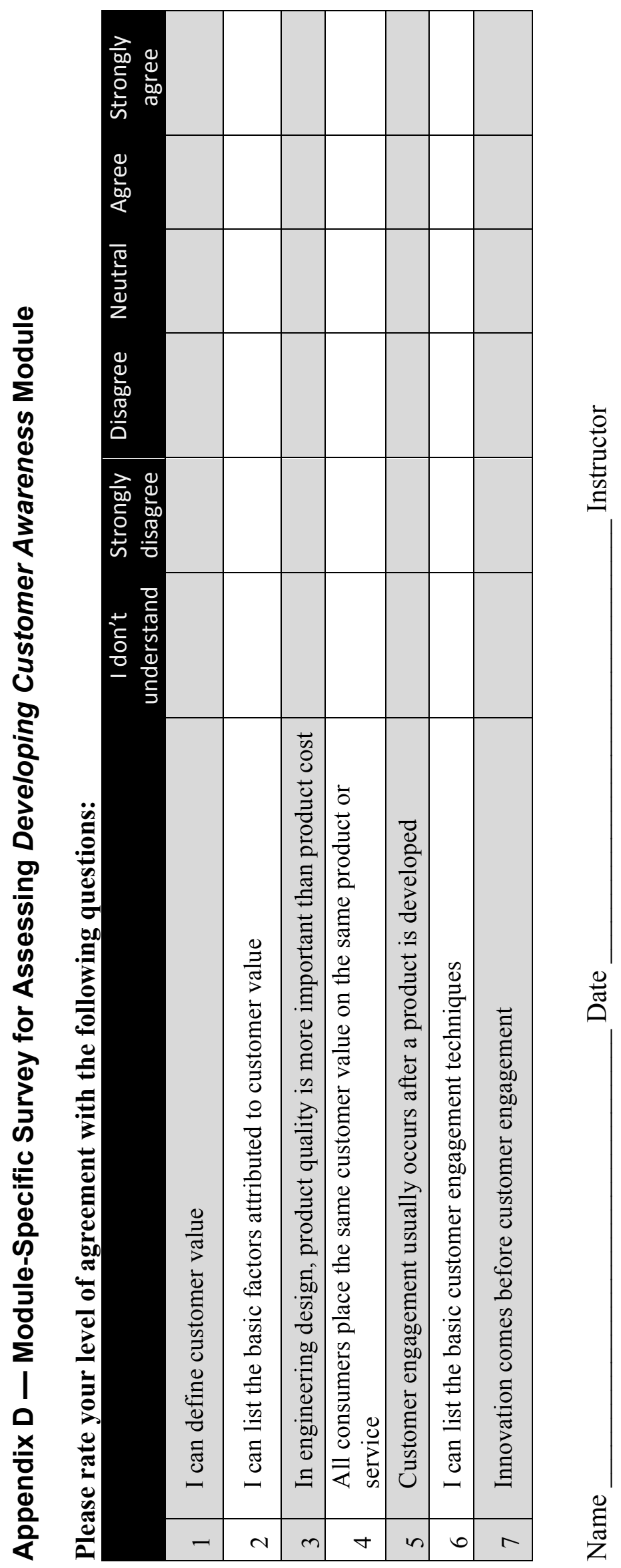

0
$\mathbb{0}$
0
0
$N$
0
$\mathbb{0}$
0
N 


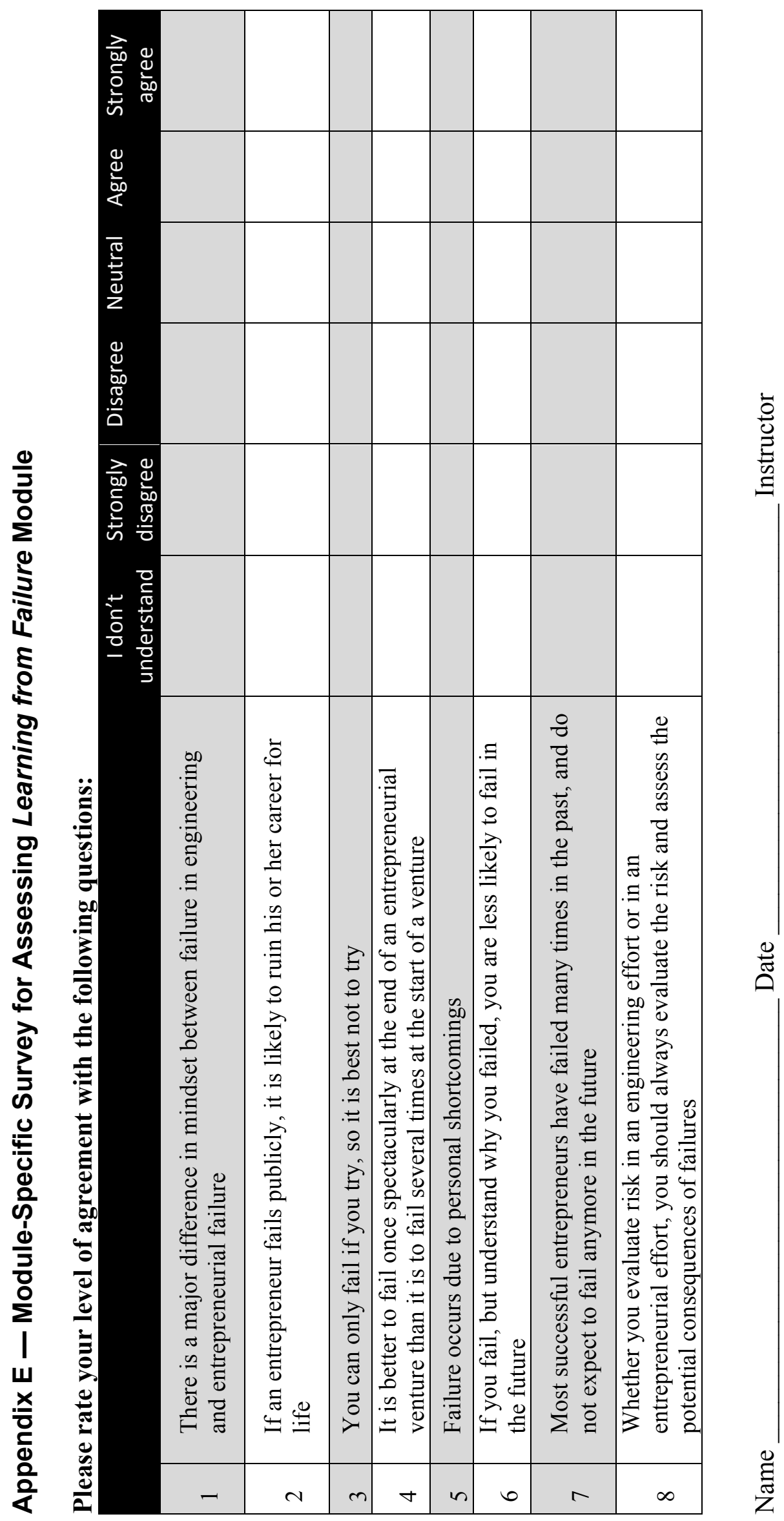

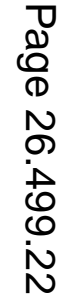

